\title{
Diffusion of solutes inside bacterial colonies immobilized in model cheese depends on their physicochemical properties: a time-lapse microscopy study
}

OPEN ACCESS

Edited by:

Jean-christophe Augustin,

Ecole Nationale

Vétérinaire d'Alfort, France

Reviewed by:

Antonio Valero,

University of Cordoba, Spain

Louis Coroller,

Université de Brest, France

${ }^{*}$ Correspondence:

Juliane Floury,

UMR Science and Technology of Milk and Eggs, INRA/Agrocampus Ouest,

65 rue de Saint Brieuc,

35042 Rennes Cx, France juliane.floury@agrocampus-ouest.fr

Specialty section:

This article was submitted to

Food Microbiology,

a section of the journal

Frontiers in Microbiology

Received: 05 February 2015

Paper pending published: 18 March 2015

Accepted: 10 April 2015

Published: 30 April 2015

Citation:

Floury J, El Mourdi I, Silva JVC, Lortal S, Thierry A and Jeanson S (2015) Diffusion of solutes inside bacterial colonies immobilized in model cheese depends on their physicochemical properties: a time-lapse microscopy

study. Front. Microbiol. 6:366.

doi: 10.3389/fmicb.2015.00366
Juliane Floury ${ }^{1,2 *}$, Ilham El Mourdi ${ }^{1,2}$, Juliana V. C. Silva ${ }^{1,2}$, Sylvie Lortal ${ }^{1,2}$, Anne Thierry ${ }^{1,2}$ and Sophie Jeanson ${ }^{1,2}$

${ }^{1}$ INRA, UMR1253 Science and Technology of Milk and Eggs, Rennes, France, ${ }^{2}$ Agrocampus Ouest, UMR1253 Science and Technology of Milk and Eggs, Rennes, France

During cheese processing and ripening, bacteria develop as colonies. Substrates and metabolites must then diffuse either from or into the colonies. Exploring how the inner cells of the colony access the substrates or get rid of the products leads to study the diffusion of solutes inside bacterial colonies immobilized in cheese. Diffusion limitations of substrates within the bacterial colony could lead to starvation for the cells in the center of the colony. This study aimed at better understands ripening at the colony level, by investigating how diffusion phenomena inside colonies vary depending on both the physicochemical properties of the solutes and Lactococcus lactis strain. Dextrans $(4,70$, and $155 \mathrm{kDa}$ ) and milk proteins (BSA, lactoferrin and $\alpha_{S 1}$-casein) of different sizes and physicochemical properties were chosen as model of diffusing solutes, and two L. lactis strains presenting different surface properties were immobilized as colonies in a model cheese. Diffusion of solutes inside and around colonies was experimentally followed by time-lapse confocal microscopy. Dextran solutes diffused inside both lactococci colonies with a non-significantly different effective diffusion coefficient, which depended mainly on size of the solute. However, whereas flexible and neutral hydrophilic polymers such as dextran can diffuse inside colonies whatever its size, none of the three proteins investigated in this study could penetrate inside lactococci colonies. Therefore, the diffusion behavior of macromolecules through bacterial colonies immobilized in a model cheese did not only depends on the size of the diffusing solutes, but also and mainly on their physicochemical properties. Milk caseins are probably first hydrolyzed by the cell wall proteases of $L$. lactis and/or other proteases present in the cheese, and then the generated peptides diffuse inside colonies to be further metabolized into smaller peptides and amino acids by all the cells located inside the colonies.

Keywords: bacterial colony, Lactoccocus lactis, cheese, confocal microscopy, diffusion, milk protein 


\section{Introduction}

During cheese making, regardless of the cheese type, bacteria are immobilized in the curd during the coagulation step, and then grow as colonies spread within the cheese curd. Jeanson et al. (2011) showed that the distribution of Lactococcus lactis colonies was random in a non-fat model cheese. Lactococci are the most used starters in the cheese industry. They are a major actor of ripening which gives the cheese its final sensorial properties. During ripening, they are responsible for the proteolysis, the milk protein breakdown, leading to peptides and amino acids. It is then obvious that the access to nitrogen sources, i.e., proteins and derivates, is of major importance for the proteolysis activity and the bacterial metabolism of the cells within the colony. However, the way the bacteria interact with dairy components is still poorly understood (Burgain et al., 2014). It is highly probable that, on one hand, milk proteins have to diffuse from the cheese matrix (a fat-protein network) into the colony to reach the bacterial cells in the center of the colony. Indeed, nutrients have to reach the center cells of the colony; otherwise these center cells may be starved. On the other hand, proteolysis end-products (small peptides and amino acids) have to diffuse from the bacterial colonies into the cheese matrix. If diffusion limitations occur inside the bacterial colony, gradients of concentration of both nitrogen sources (low concentrations in the center of the colony) and nitrogen end-products (high concentrations in the center of the colony) may be generated and may affect the metabolic activity of microbial cells, and thus the kinetics of the ripening process. The mean diameters of colonies and the mean distance between them in a model cheese were shown to be strongly influenced by the initial inoculation level. The lower the inoculation level was, the larger the colonies were, and then the further away they were from each other (Jeanson et al., 2011). It has previously been observed that low concentration of substrates could generate different physiological states or different growth rates in pathogenic bacterial colonies when colonies were bigger than $400 \mu \mathrm{m}$ diameter (McKay et al., 1997; Kreft et al., 1998). The main hypothesis for these observations was that the diffusion limitations of substrates within the bacterial colony lead to starvation for the cells in the center of the colony. As a consequence, lysis could be higher for the center cells in Vibrio cholera colonies (Wimpenny, 1992). If lysis occurs at the center of the colony, it is also very important to know if bacterial enzymes could diffuse out of the colony to determine how far from the colony proteolytic enzymes could diffuse outside the colony, in the cheese matrix.

However, Floury et al. (2010) reported a strong lack of data about the diffusion properties of key molecules like sugars, organic acids, proteins, and peptides in cheese. The first effective diffusion coefficient was determined for nisin in model cheeses (Aly et al., 2011). Using fluorescently labeled solutes, Silva et al. (2013) showed that dextran macromolecules up to $2 \mathrm{MDa}$, and different dairy proteins, were able to diffuse through the model cheese. Quite interestingly, the proteins tested (rigid and negatively charged molecules) were hindered to a greater degree than the dextrans (flexible and neutral molecules) in the model cheese, due to specific interactions between the protein matrix and the diffusing proteins. So far, only our previous study (Floury et al., 2013) has investigated the diffusion of molecules within bacterial colonies. Even if it has been demonstrated that viral particles such as bacteriophages $(\approx 100 \mathrm{~nm}$ head $)$ could diffuse inside biofilms (Lacroix-Gueu et al., 2005; Briandet et al., 2008), we consider that the structure of biofilms (with exopolysaccharide matrix) and colonies is not really comparable. It was then very important to understand ripening at the colony level by investigating the diffusion of model nutrient macromolecules, such as polysaccharides and milk proteins, inside lactococci colonies.

In our previous study (Floury et al., 2013), we developed a specific experimental design and we demonstrated for the first time that model solutes of different sizes (dextran macromolecules from 4.4 to $155 \mathrm{kDa}$ ) were able to diffuse inside bacterial colonies of $L$. lactis, immobilized in two different models of solid food matrices (model cheese and agar). The principle of this static design was to deposit a solution of the fluorescentlylabeled diffusing solute on the upper side of a gel cassette (Brocklehurst, 1995) filled with the solid medium, previously inoculated with $L$. lactis. The gel cassettes were then directly observed by confocal laser microscopy and the corresponding relative fluorescence intensity profiles within the colony vs. in the surrounding media were quantified after $3 \mathrm{~h}$ of diffusion of the fluorescent solutes at $19^{\circ} \mathrm{C}$. It was concluded that colonies of $L$. lactis LD61 immobilized in the model cheese were porous to all dextrans from 4 to $155 \mathrm{kDa}$ after this delay of migration, but no kinetic aspect of diffusion could be assessed.

The objective of the present work was to determine how diffusion phenomena inside colonies vary depending on both the properties of solutes and L. lactis strain. We quantified the diffusion rates of solutes of different sizes and physico-chemical properties both around and inside colonies immobilized in a model cheese, for two Lactococcus lactis strains presenting different surface properties. Our experimental device was improved by adapting the time-lapse microscopy method described in Rani et al. (2005), originally developed to determine the effective diffusion coefficients of fluorescent tracers into biofilm cell clusters of Staphylococcus epidermis and their surrounding solution.

\section{Materials and Methods}

\section{Bacterial Strains and Growth Conditions}

Lactococcus lactis subsp. lactis biovar diacetylactis LD61 was used (collection of the Centre International de Resources Microbiennes-Bactéries d'Intérêt Alimentaire (CIRM-BIA), INRA, Rennes, France) and was routinely grown under static conditions in M17 lactose broth (Difco, Becton Dickinson, Le Pont de Claix, France) at $30^{\circ} \mathrm{C}$.

Lactococcus lactis subsp. lactis TIL1230 was kindly given M-P Chapot-Chartier and obtained from the parental strain NCDO2110 (Giaouris et al., 2009). This strain was lactose and protease negative and was then grown under static conditions in M17 lactose broth supplemented with $0.5 \%$ glucose (Sigma) at $30^{\circ} \mathrm{C}$. Therefore, to ensure its optimal growth in milk, the milk 
cultures of TIL1230 were supplemented with $1 \%$ glucose (Sigma) and $0.3 \%$ peptone casein $(\mathrm{BD})$.

\section{Bacterial Surface Characterization Cell Surface Hydrophobicity}

Net surface charge of the bacteria and the presence of lipophilic compounds affect partitioning between two immiscible liquids (Burgain et al., 2014). The microbial adhesion to solvents (MATS) method was employed for the evaluation of the hydrophobic/hydrophilic character of the cell surface of L. lactis strains and for their Lewis acid-base characteristics. On this basis, we selected chloroform, a monopolar and acidic solvent (electron acceptor) and hexadecane, an apolar alkane using the protocol fully described in Giaouris et al. (2009). The values of MATS obtained with the chloroform were regarded as a measure of electron donor/basic characteristics of bacteria. Adhesion ability of the bacteria to the solvent is expressed as a percentage (\%) according to the following relation:

$$
\% \text { adhesion }=\frac{O D_{400}^{\text {initial aqueous phase }}-O D_{400}^{\text {aqueous phase after mixing }}}{O D_{400}^{\text {initial aqueous phase }}}
$$

With OD the optical density of the bacterial suspension measured at $400 \mathrm{~nm}$. Each measurement was performed in triplicate and the experiment was repeated twice with independent bacterial cultures.

\section{Cell Surface Charge}

The electrophoretic mobility (EM) was measured to determine the cell surface net charge of the two bacteria according to the protocol described in Boonaert and Rouxhet (2000). EM of the bacteria with the appropriate $\mathrm{pH}$ values were measured at room temperature on a Zetameter model (Zeta Sizer Nano Series, Malvern Instruments Ltd, Malvern, UK). Experiments were made twice with independent culture with triplicate measurements. EM was expressed in $10^{-8} \mathrm{~m}^{2} / \mathrm{V}$.s.

\section{Preparation of the Model Cheese in Imaging Chambers}

A fat-free cheese made from renneted concentrated skim milk was used as model cheese, as previously described in Floury et al. (2013). This non-fat model cheese has the great advantage over traditional cheese technology to be a repeatable and homogeneous cheese matrix. Moulded after renneting, it is coagulated without further syneresis of the gel, thus exhibiting highly reproducible micro- and macro- structural properties. The concentrated milk was inoculated for a final concentration of $10^{5} \mathrm{CFU} / \mathrm{ml}$, and coagulant agent (Maxiren 180; DSM Food Specialities, Seclin, France) was added at a final concentration of $300 \mu \mathrm{l} / \mathrm{l}$. After homogenization, $400 \mu \mathrm{l}$ of the mixture was slowly poured into several CoverWell imaging chambers (SigmaAldrich, Saint-Quentin Fallavier, France) that allow direct observation under the confocal microscope (Floury et al., 2012). The imaging chambers with the model cheese were then vertically incubated at $30^{\circ} \mathrm{C}$ for $15 \mathrm{~h}$ for coagulation and growth of the $L$. lactis LD61. For the L. lactis TIL1230, imaging chambers were also vertically incubated, for $8 \mathrm{~h}$ at $30^{\circ} \mathrm{C}$ and then for $15 \mathrm{~h}$ at $19^{\circ} \mathrm{C}$.
In parallel, the same media were also inoculated in $30 \mathrm{ml}$-bottles to measure the $\mathrm{pH}$ during acidification by L. lactis. The $\mathrm{pH}$ of the model cheeses were $5.05 \pm 0.06$, and $5.32 \pm 0.10$ for LD61 and TIL1230, respectively, after $15 \mathrm{~h}$ of incubation.

\section{Fluorescent Dyes and Labeled Solutes}

SYTO ${ }^{\mathrm{TM}}$ was added before coagulation of the model cheese to a final concentration of $1.2 \mu \mathrm{mol} / \mathrm{l}$, in order to dye the bacterial cells and to visualize colonies within the opaque matrix of cheese. SYTO9 ${ }^{\mathrm{TM}}$ penetrates all bacterial membranes and dies all the bacterial cells, alive, and damaged (Boulos et al., 1999).

Three Rhodamine B isothiocyanate (RITC) conjugated dextrans of 10,70 , and $155 \mathrm{kDa}$ were chosen as model of flexible and neutral polymers of anhydroglucose of different sizes (Table 1), labeled with an extent of labeling from 0.002 to 0.015 mol RITC per mol glucose (Sigma-Aldrich, Saint-Quentin Falavier, France). RITC-dextrans were dissolved to $50 \mathrm{mg} / \mathrm{ml}$ in distilled water.

The studied set of solutes was completed with three milk proteins, one random coil milk protein, the $\alpha_{S 1}$-casein (INRA, Rennes, France), and two globular dairy proteins, bovine serum albumin (BSA, Sigma-Aldrich, Saint-Quentin Falavier, France) and lactoferrin (LF, Fonterra Boulogne-Billancourt, France). The proteins were labeled with free RITC (Sigma) using the protocol described in Silva et al. (2013). The three solutions were lyophilized and labeling efficiencies were determined by mass spectroscopy. BSA, LF, and $\alpha_{S 1}$-casein were mainly mono-labeled with RITC. Finally, the RITC-labeled solutes were either dissolved to $50 \mathrm{mg} / \mathrm{ml}$ in water for the dextrans and the lactoferrin, in a permeate solution obtained from the ultrafiltration of skimmed milk for $\alpha_{S 1}$-casein, and in a $0.1 \mathrm{M}$ BisTris buffer at $\mathrm{pH} 6.8$ for the BSA.

The solutions of labeled solutes were stored at $-20^{\circ} \mathrm{C}$, protected from light before and during fluorescence measurements.

Physicochemical properties of the solutes are summarized in Table 1.

TABLE 1 | Physicochemical properties of the fluorescently-labeled solutes.

\begin{tabular}{|c|c|c|c|c|c|c|}
\hline & \multicolumn{3}{|c|}{ Dextran } & \multirow[t]{2}{*}{ BSA } & \multirow[t]{2}{*}{ Lactoferrin } & \multirow[t]{2}{*}{$\alpha_{\mathbf{S 1}}$-casein } \\
\hline & 10 & 70 & 155 & & & \\
\hline $\begin{array}{l}\text { Molecular } \\
\text { weight } \\
(\mathrm{kDa})\end{array}$ & 10 & 70 & 155 & $66.4^{a}$ & $77^{\mathrm{b}}$ & $23.6^{c}$ \\
\hline $\begin{array}{l}\text { Isolectrical } \\
\text { point }\end{array}$ & - & - & - & $\approx 5^{a}$ & $8-9^{b}$ & $4.94^{d}$ \\
\hline $\begin{array}{l}\text { Hydrodynamic } \\
\text { radius (nm) }\end{array}$ & $2.3^{\mathrm{e}}$ & $6^{e}$ & $8.5^{\mathrm{e}}$ & 3.65 & $2.2^{f}$ & $2.9^{C}$ \\
\hline Flexibility & & flexible & & & rigid & flexible \\
\hline Hydrophobicity & & hydrophilic & & & drophobic & amphiphile \\
\hline
\end{tabular}




\section{Experimental Device for Solute Diffusion Experimental Set-up}

After the incubation time necessary for bacterial growth, a concentration gradient of the fluorescently-labeled solutes between the surface of the imaging chamber and the model cheese was triggered in order to induce the diffusion phenomenon. Five microliter of the fluorescently-labeled dextran or protein solution was dropped off at the surface of the coagulated model cheese and left to diffuse for $5 \mathrm{~min}$ throughout the surrounding medium, in the dark and in an air-conditioned room at $19^{\circ} \mathrm{C}$. Solute diffusion into the model cheeses began as soon as the fluorescent solution was left in contact with the surface of the cheese $(t=0)$. The fluorescent solutes diffuse into the gel by a plane one-dimensional diffusion mechanism (Figure 1).

\section{Time-Lapse Confocal Laser Scanning Microscopy}

Model cheese samples were imaged on an inverted NIKON Eclipse-TE2000-C1si microscope allowing confocal laser scanning microscopy (NIKON-France, Champigny sur Marne, France), with an oil-immersion $40 \times$ objective at $512 \times 512$ pixel resolution. Ten minutes after the deposit of the fluorescent solution containing the diffusing solutes, the first step was to localize a fluorescently (SYTO9 ${ }^{\mathrm{TM}}$ ) labeled colony, that had grown both in a focal plane at $10-15 \mu \mathrm{m}$ depth from the coverslip and at a quite close distance from the surface of the gel, in order to visualize the diffusion front of fluorescence of the RITC-labeled solutes in a reasonable time-scale. SYTO ${ }^{\mathrm{TM}}$ fluorescence was excited with the $488 \mathrm{~nm}$ laser and detected between 500 and $530 \mathrm{~nm}$. The second step was to obtain the kinetic of the diffusion process of the RITC labeled solutes thanks to the acquisition of images of the fluorescent front of diffusion around and into the target bacterial colony every 5-15 $\mathrm{min}$ for at least $2 \mathrm{~h}$. Fluorescently RITC-labeled dextrans and proteins were excited at $543 \mathrm{~nm}$ wavelength, and fluorescence emission was detected between 565 and $615 \mathrm{~nm}$. All experiments were performed at $19^{\circ} \mathrm{C}$ using a temperature-regulated platform and air-conditioned room and were performed at least in triplicate.

\section{Estimation of Diffusion Coefficients}

Images obtained after a time series of acquisition were analyzed using ImageJ software. A line measuring 512 pixels long and 10 pixels wide was drawn through the axial diameter of the colony in

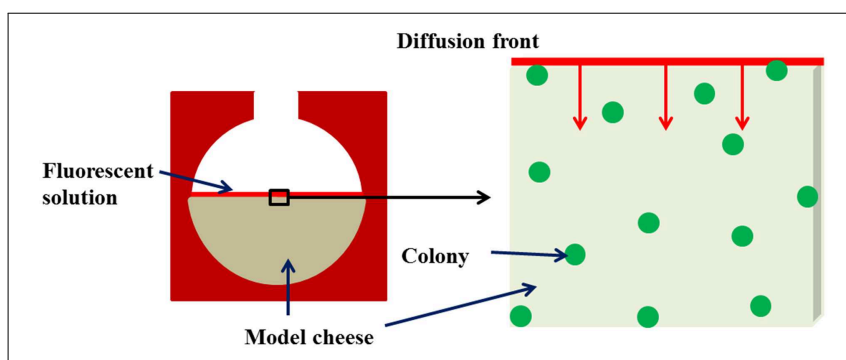

FIGURE 1 | Diagram of the experimental device for monitoring the kinetics of diffusion of solutes around and inside colonies immobilized in the model cheese. order to quantify the profile of RITC fluorescence intensity (also named gray-level value) along the direction of the diffusion front and at each acquisition time. The resulting fluorescence intensity profiles vs. time were then exported into a single spreadsheet.

According to Crank (1975), in the case of a plane one-dimensional diffusion, induced by an instantaneous source and after a short time $t$ of diffusion, the concentration gradient of the investigated solute is given by the following relationship:

$$
C(x, t)=\frac{M}{8 \sqrt{\pi D t}} \exp \left(-\frac{x^{2}}{4 D t}\right)
$$

where $C$ is the concentration expressed as the amount of diffusing solute per unit area of surface, $x$ is the perpendicular axis to the surface of the model cheese in $\mu \mathrm{m}$ ( $x=0$ corresponded to the surface), $t$ is the time, $D$ is the diffusion coefficient and $M$ is the surface concentration of the diffusing solute, which corresponds to the total amount of the investigated fluorescently labeled solute in the gel related to the gel surface unit. This concentration $M$ was considered as constant since it was in great excess compared to its concentration inside the cheese and as there was no reaction between the investigated component and the model cheese.

Equation (2) can be linearized:

$$
\operatorname{Ln}(C(x))=\operatorname{Ln}\left(\frac{M}{8 \sqrt{\pi D t}}\right)-\frac{x^{2}}{4 D t}
$$

The diffusion coefficient $D$ was estimated from the slope of the straight line $\operatorname{Ln}(C(x))$ vs. $x^{2}$, equal to $-1 /(4 D t)$. The slopes of the lines inside and outside the colonies were obtained by performing a linear regression with the best-fit linear trend function in Microsoft Excel using the least-squares method. Two effective diffusion coefficients $D_{\text {out }}$ and $D_{\text {in }}$ were quantified from the concentration profiles around the bacterial colony $\left(D_{\text {out }}\right)$ and inside the bacterial colony $\left(D_{\text {in }}\right)$. Both $D_{\text {out }}$ and $D_{\text {in }}$ were determined from the concentration profiles (gray values or fluorescence intensity profiles) obtained at a short time of diffusion, i.e., $30 \mathrm{~min}$ after the deposit, of the fluorescent solution at the surface of the model cheese.

\section{Statistical Analysis}

One-Way analysis of variance (ANOVA) and Tukey's paired comparison test were applied to the diffusion coefficient data in order to determine which mean values were significantly different from one another at the $95 \%$ confidence level using the R software package (version R i386 3.0.2).

\section{Results and Discussion}

\section{Surface of Both Lactoccoci Strains Are Hydrophilic, but TIL1230 is More Electronegative than LD61 at the pH of the Model Cheese}

The first step of the strategy of this study was to determine the hydrophobic/hydrophilic character, Lewis acid-base interactions, and electrostatic cell surface properties. The MATS method and EM measurements gave us information on the potential ability of 
TABLE 2 | Results of the microbial adhesion to solvents (MATS) method*.

\begin{tabular}{lrr}
\hline \multirow{2}{*}{ L. lactis strain } & \multicolumn{2}{c}{$\%$ of adhesion to } \\
\cline { 2 - 3 } & \multicolumn{1}{c}{ Hexadecane } & Chloroform \\
\hline LD61 & $8.6 \pm 5.2(n=4)$ & $11.3 \pm 9.8(n=3)$ \\
TIL1230 & $12.8 \pm 5.3(n=6)$ & $13.7 \pm 2.5(n=5)$ \\
\hline
\end{tabular}

${ }^{*}$ The results are expressed as the mean \pm one standard deviation of $n$ independent measurements.

the two L. lactis strains to generate physicochemical interactions between both the cheese matrix and the diffusing solutes.

Results of the MATS method are reported in Table 2.

The partitioning of cells between aqueous and hexadecane is a direct measurement of the cell surface hydrophobicity or hydrophilicity. The surface property of a cell can be considered as hydrophilic if its affinity for apolar hexadecane is below 40\% (Giaouris et al., 2009). As shown in Table 2, the percentage of adherent cells to hexadecane was slightly higher (not significantly) for TIL1230 than for LD61, with values largely inferior to $20 \%$ for both $L$. lactis strains, demonstrating a clear hydrophilic character of their surface. The hydrophilic character of bacteria is largely due to the nature of the compounds present on the surface, useful for adhesion (Burgain et al., 2014).

The percentages of bacterial adhesion to the chloroform, an acidic solvent and electron acceptor, were not significantly different between the two L. lactis strains, with values also inferior to $20 \%$ (Table 2). These results are in agreement with values of adhesion to chloroform obtained on various L. lactis strains by Ly et al. (2006) and Giaouris et al. (2009).

The electrophoretic mobilities (EM) of the two L. lactis strains at different $\mathrm{pH}$ values indicated that the isoelectric points were around $\mathrm{pH} 2.5$ and 4.5 for TIL1230 and LD61 strains, respectively (Figure 2). Between $\mathrm{pH} 2$ and 6, the EM of L. lactis TIL1230 drastically decreased by about $4 \times 10^{-8}$, whereas it decreased only $0.4 \times 10^{-8} \mathrm{~m}^{2} /$ V.s for LD61. $L$. lactis TIL1230 has a greater EM above $\mathrm{pH} 3$ than LD61. Interestingly, LD61 strain presented EM very close to zero at all $\mathrm{pH}$ values tested, revealing very low electronegative cell surface in those conditions. In contrast, L. lactis TIL1230 was found to be highly negatively charged at $\mathrm{pH}$ between 4 and 6 , as previously observed for most of L. lactis strains, with same order of magnitude for EM values, ranging from -2 to $-5 \times 10^{-8} \mathrm{~m}^{2} / \mathrm{V} . \mathrm{s}$ (Ly et al., 2006; Habimana et al., 2007; Giaouris et al., 2009). Giaouris et al. (2009) reported for the first time that some lactic acid bacteria possess a very low surface electronegativity around neutral $\mathrm{pHs}$, as observed here for $L$. lactis LD61. This diversity in the global charge of lactococcal cell surface may be linked to the variability of the molecules containing ionized groups in the cell envelope. Three types of ionized groups are considered to determine the surface electrical properties of L. lactis: phosphate groups present in teichoic and lipoteichoic acids, and carboxylate and protonated amino groups of proteins (Boonaert and Rouxhet, 2000). It has been previously shown that the expression of the major cell wallanchored protease was responsible for altering L. lactis surface physicochemical properties, shifting the cell envelope from a

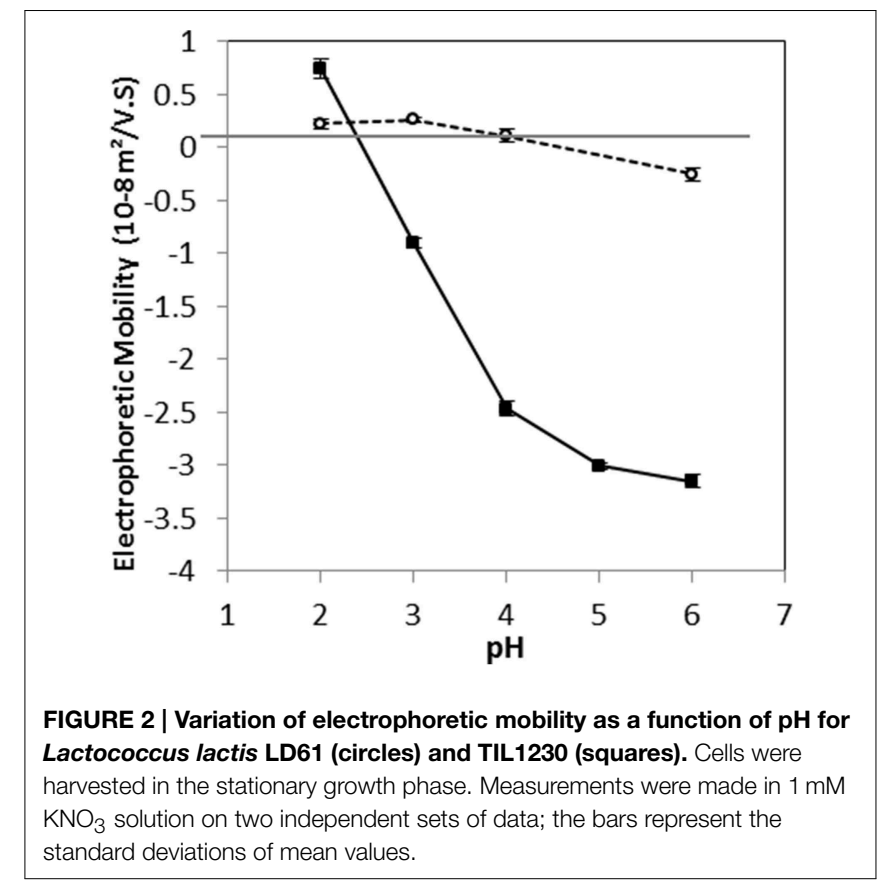

hydrophilic surface to an extremely hydrophobic one, going along with an increase of negative charges at the cell surface (Habimana et al., 2007). In the present study, the two strains of L. lactis LD61 and TIL1230 were thus supposed to present greater differences in their cell surface properties as TIL1230 does not possess the cell wall protease and LD61 does. Obviously, the global property of the cell surface is multi-causal and then difficult to predict.

Bacterial cell wall properties were shown to affect diffusion particles of nanoparticles inside biofilm matrices of L. lactis (Habimana et al., 2011). They measured that the diffusion of $50-\mathrm{nm}$ radius particles of anionic carboxylate-modified fluorescent polystyrene beads was more hindered in biofilm matrix of $L$. lactis which possessed the anchored protease. Based on these results, the present study aimed at comparing the diffusion of solutes of different charge, flexibility, and hydrophobicity, inside immobilized colonies (in cheese) of two different L. lactis strains presenting (LD61) or not (TIL1230) the anchored protease in their cell walls.

\section{Diffusion Coefficients of Dextrans Inside the Colonies Depend on the Solute Size but Not on the Lactococci Strains}

Figure 3A shows typical confocal microscopic observations of L. lactis colonies, immobilized in the model cheese, and visualized at different times after the deposit of the $70 \mathrm{kDa}$ fluorescently-labeled dextran solution. The images obtained with L. lactis TIL1230 and the two other fluorescently-labeled dextrans (10 and $155 \mathrm{kDa}$ ) were similar and are thus not shown here. Both lactococci strains grew in this model cheese as perfect spheres with diameters around $30-40 \mu \mathrm{m}$, as previously reported in Jeanson et al. (2011) and Floury et al. (2013). Figure 3A also clearly shows the progressive increase of the red 


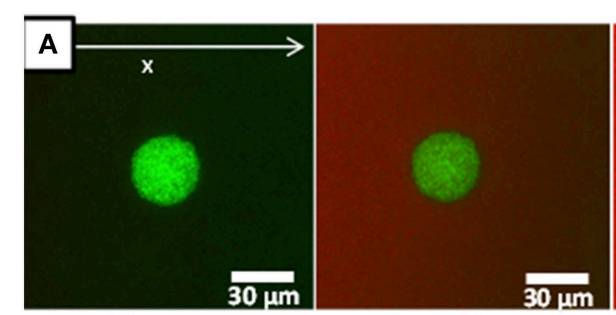

$10 \mathrm{~min}$
$30 \mathrm{~min}$

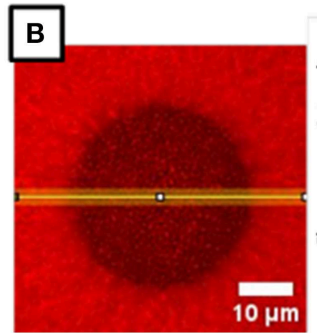

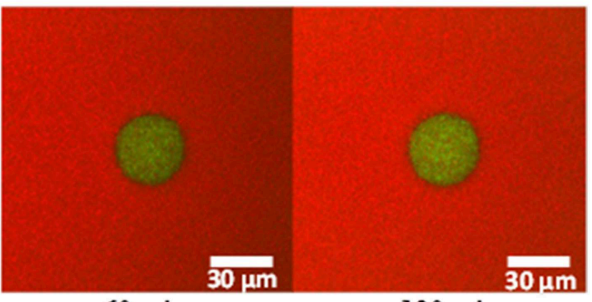

$60 \mathrm{~min}$

$120 \mathrm{~min}$

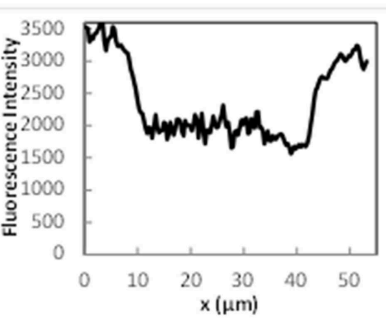

FIGURE 3 | (A) Example of a time-lapse microscopic observations of a Lactococcus lactis LD61 colony immobilized in a model cheese after $15 \mathrm{~h}$ growth at a temperature of $30^{\circ} \mathrm{C}$ during diffusion of a RITC-labeled dextran (here RITC-Dextran $70 \mathrm{kDa}$ ). L. lactis cells are colored in green, RITC-dextran in red. (B) Focus on the microscopic observation of the fluorescence intensity of RITC-dextran inside and around a $L$. lactis LD61 colony immobilized in a model cheese at $t=120$ min of diffusion and the corresponding fluorescence intensity profile along a 10 pixels wide line vs. position $x$. Black zones in the colony corresponds to the L. lactis cells. fluorescence both along the $\mathrm{x}$-axis and through time, proving that the fluorescent solute progressively moved inward toward a Lactococcus colony because of the concentration gradient between the surface and the interior of the model cheese. After $2 \mathrm{~h}$ of diffusion (Figure 3B), the red color was uniform in all the directions around the colony, meaning that the concentration of the fluorescently-labeled solute had reached a plateau. The diffusing process ended because there was no more concentration gradient in this area. The simple observation of these time series of images also suggests that the hypothesis of unidirectional diffusion of solute is valid. Therefore, image analysis of the intensity profiles of red fluorescence along this $\mathrm{x}$ axis allowed to directly quantifying the diffusive penetration of the solutes as a function of time (Figure 3B). Typical fluorescence intensity profiles were obtained (Figures 4 A-C) at different times (between 20 and $150 \mathrm{~min}$ ). Only an example of the fluorescence intensity profiles obtained with TIL1230 strain was shown on Figure 4D because the profiles were very similar to those obtained with LD61.

From all these fluorescence intensity data as a function of the position and the time of diffusion, we calculated the corresponding relative fluorescence intensity by dividing the fluorescence intensity at each position $\mathrm{x}$ by the average fluorescence intensity obtained on the region upstream the colony. An example is given on Figure $4 \mathrm{E}$ for the diffusion of the $70 \mathrm{kDa}$ dextran in a colony of L. lactis LD61. The relative fluorescence intensity profiles obtained with the other dextrans and with the other strain were very similar (data not shown). The purpose of this graphical representation of the results was to observe the evolution of the ratio of the fluorescence intensity in the colony vs. outside the colony as a function of time.
As shown on Figure 4E, whatever the time of diffusion considered, the fluorescence intensity inside the colony of both L. lactis strains drastically dropped compared to the fluorescence intensity in the surrounding cheese matrix, with a quite constant ratio around $0.4-0.6$ depending on the $\mathrm{x}$-axis position inside the colony. We previously showed that even the fluorescentlylabeled solutes diffuse inside a bacterial colony (Floury et al., 2013), but do not penetrate into the bacterial cells. Furthermore, dextrans are not metabolized by lactococci cells. Thus, the only way to explain this drop of relative fluorescence intensity inside the colony is because on the line of 10-pixel wide (Figure 3B), the volume filled with the fluorescent solution is lower inside the colony than outside the colony due to the presence of the bacterial cells (corresponding to black zones with no fluorescence intensity). So even if the experimental fluorescence intensity is different, the real concentration of the fluorescent solute is effectively the same both inside and around the colony. The calculated average value represented by the relative fluorescence intensity profiles was quite stable along the $\mathrm{X}$-axis inside the colonies for the fluorescently-labeled dextran solutes (Figure 3B), and this was also true whatever the time of diffusion considered (Figure 4E).

The concentration of the diffusing solute cannot be calculated from experimental data. The fluorescent intensity is, however, proportional to the diffusing solute concentration. Then, assuming a one-dimensional Fickian diffusion induced by an instantaneous source, the effective diffusion coefficients both inside the colony and in the surrounding matrix could be estimated from the slope of the linearization of the experimental fluorescence intensity profiles obtained a short time after the beginning of the diffusive process, with $D=-\frac{1}{4 . t . s l o p e}$ from Equation (3). A typical linearized curve and the corresponding 

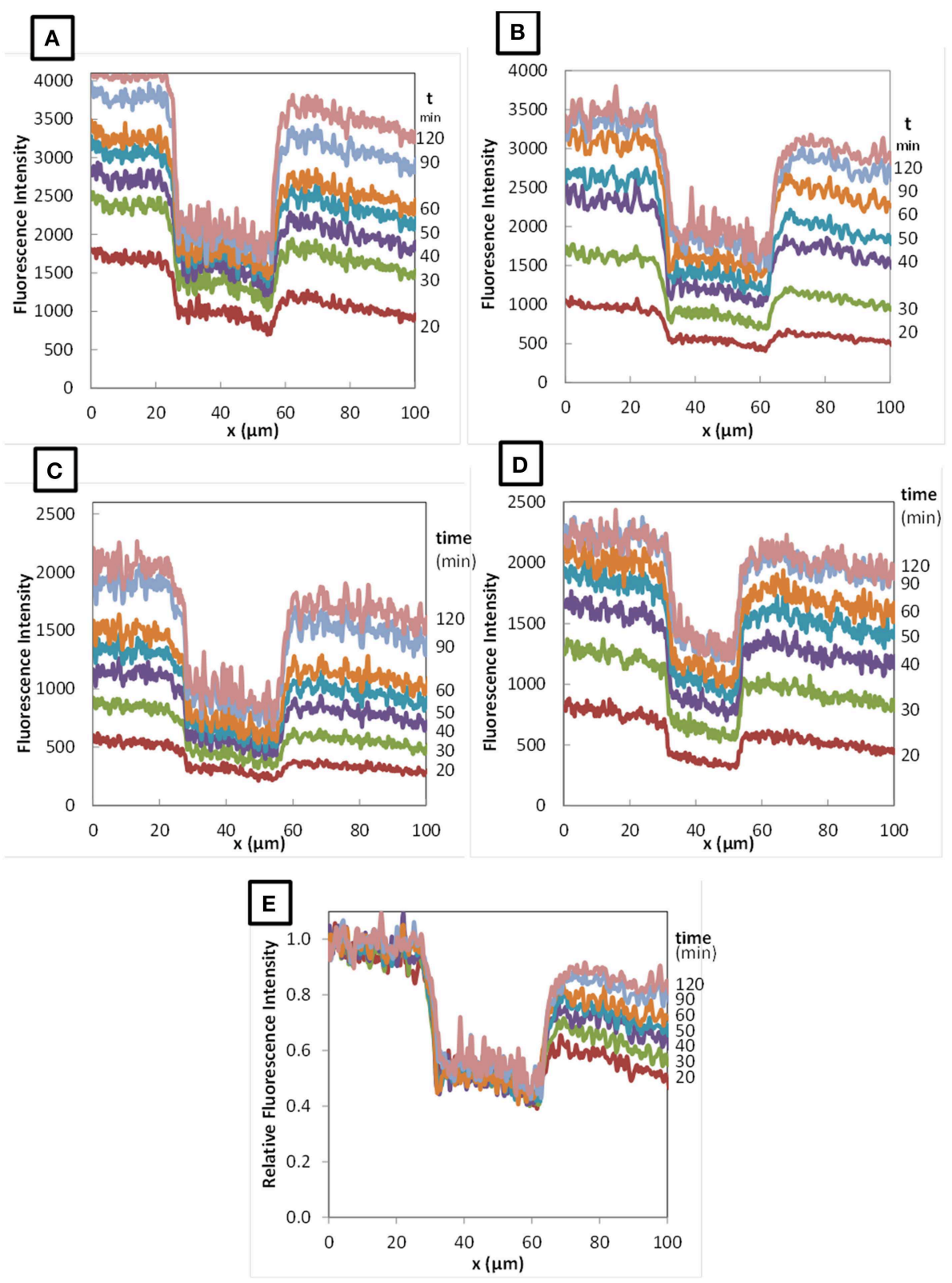

FIGURE 4 | Profiles of fluorescence intensity during diffusion of RITC-dextran $10 \mathrm{kDa}$ (A), $70 \mathrm{kDa}$ (B), and $155 \mathrm{kDa}$ (C) in colonies of Lactococcus lactis LD61 and of RITC-dextran $70 \mathrm{kDa}$ in
TIL1230 (D) as function of diffusion time (from 20 to $120 \mathrm{~min}$ ). (E) Typical relative fluorescence intensity profile obtained with RITC-dextran $70 \mathrm{kDa}$ in LD61. fitted equations obtained both outside and inside the colony are shown on Figure 5. Regression coefficients of the linear models were generally higher than 0.9 in the surrounding matrix, and slightly lower inside the colony with values around 0.7 because of a lower signal to noise ratio inside colonies. The slope of the line was clearly higher inside than outside the colony (Figure 5), suggesting that the diffusion of solutes was slower inside the colony. The diffusion of the fluorescent solute was probably more hindered inside the colony, most likely because of the high volume filled with the bacterial cells, than in the protein-network of the surrounding matrix.
The mean effective diffusion coefficients $\left(D_{\text {eff }}\right)$ of the different RITC-dextrans were obtained using this modeling approach, both inside and outside the colonies of the two bacterial strains (Figure 6). $D_{\text {eff }}$ were significantly $(p<0.05)$ lower inside the colonies than in the surrounding matrix. When $D_{\text {eff }}$ were plotted against the hydrodynamic radius, linear relationships $\left(R^{2}>0.8\right)$ were obtained over the molecular weight range of $10-155 \mathrm{kDa}$, both inside and outside colonies. The statistical analysis (ANOVA) performed on the estimated values revealed that the values of $D_{\text {eff }}$ were not significantly different $(p<0.001)$ between the two bacterial strains, meaning that dextran solutes 


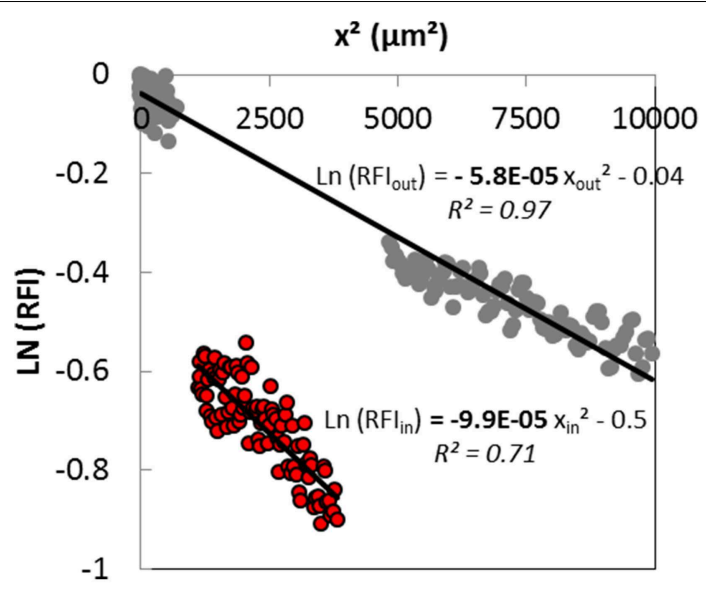

FIGURE 5 | Typical linearized curve obtained $30 \mathrm{~min}$ after the deposit of the fluorescent solution containing a $70 \mathrm{kDa}$ dextran at the surface of the model cheese inoculated with Lactococcus lactis LD61. Lines correspond to the linear fit of experimental data both outside (gray circles) and inside the colony (red circles).

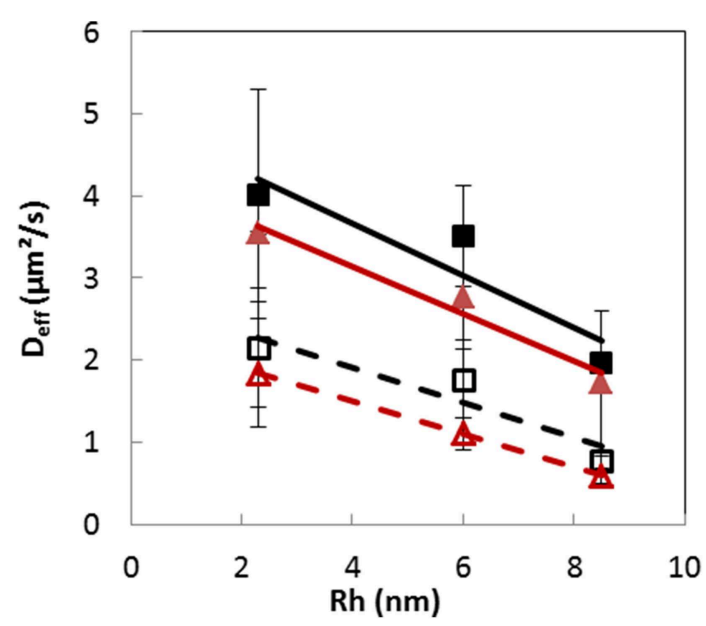

FIGURE 6 | Plots of the mean effective diffusion coefficients $\left(D_{\text {eff }}\right)$ of dextrans 10,70 , and $155 \mathrm{kDa}$ vs. their respective hydrodynamic radius, estimated from experimental data obtained after $30 \mathrm{~min}$, both inside (open symbols) and outside (plain symbols) colonies of Lactoccus lactis LD61 (squares) and TIL1230 (triangles) in a model cheese. Lines, linear regression.

diffused inside both Lactocci colonies with a similar diffusion coefficient, which depended mainly on size of the solute. The absence of significant difference between both $L$. lactis strains was expected because dextrans are known to be hydrophilic macromolecules and the surface properties of the two different cells were shown to be also both very hydrophilic.

In the present study, we went further than the previous study (Floury et al., 2013) by visualizing the kinetic of the diffusion process inside the colonies. Moreover, we were able to estimate diffusion coefficients of the dextran solutes inside the microbial colonies from image analysis of the data. As shown in Table 3, whatever their size between 10 and $155 \mathrm{kDa}$ and the Lactoccocus
TABLE 3 | Calculated ratios of effective diffusion coefficients of dextrans obtained inside and outside $L$. lactis colonies $\left(D_{\text {in }} / D_{\text {out }}\right)$, of diffusion coefficients of dextrans in water* vs. inside colonies $\left(D_{\mathrm{w}} / D_{\text {in }}\right)$, and corresponding tortuosity indices, calculated as square root of $D_{\mathrm{w}} / D_{\mathrm{in}}$.

\begin{tabular}{lcccccc}
\hline Dextran & \multicolumn{2}{c}{$\boldsymbol{D}_{\text {in }} / \boldsymbol{D}_{\text {out }}$} & \multicolumn{2}{c}{$\boldsymbol{D}_{\mathbf{w}}{ }^{*} / \boldsymbol{D}_{\text {in }}$} & \multicolumn{1}{c}{ Tortuosity index } \\
\cline { 2 - 7 } & \multicolumn{7}{c}{ L. lactis strain } \\
\cline { 2 - 7 } & LD61 & TIL1230 & LD61 & TIL1230 & LD61 & TIL1230 \\
\hline 10 & 0.54 & 0.52 & 43 & 50 & 6.6 & 7.1 \\
70 & 0.50 & 0.40 & 20 & 32 & 4.5 & 5.7 \\
155 & 0.40 & 0.34 & 32 & 43 & 5.7 & 6.5 \\
\hline
\end{tabular}

${ }^{*} D w$ values at $20^{\circ} \mathrm{C}$ calculated by using the Stokes-Einstein relationship.

strain, the effective diffusion coefficients of dextrans obtained inside the colonies were around twice lower than their respective diffusion coefficients in the surrounding cheese matrix around the colonies, and up to 50 times smaller than those in water $D_{\mathrm{w}}$ (calculated from the Stokes-Einstein equation). Silva et al. (2013) also found that effective diffusion coefficient values of fluorescein isothiocyanate (FITC)-dextrans (from 4 to $2000 \mathrm{kDa}$ ) in the same model cheese, but not inoculated, were smaller than those in water due to the hindrance of the protein network. However, their values of effective diffusion coefficients were between 4 and 9 times larger than in the present study, depending of the size of the dextran.

The variability observed has two major causes. The first source of variability is the experimental approaches used to estimate diffusion coefficients (Floury et al., 2010). Effective diffusion coefficients estimated thanks to the concentration profiles method in the present method are then difficult to compared to the so called "self-diffusion" coefficients obtained using the FRAP technique in Silva et al. (2013).

The second source of variability is the model cheese. Indeed, even if the model cheese had the same initial composition in both studies, the metabolism of the lactococci inoculated in the present study induced a strong decrease of cheese $\mathrm{pH}$ from 6.6 to 5.1-5.3, depending on the L. lactis strain, which probably modified to some extent the microstructure of the protein network and then the diffusion behavior of the solutes in both cheeses.

In agreement with our results, Guiot et al. (2002) and Thurnheer et al. (2003) observed that the diffusion coefficients of fluorescently-labeled dextrans from 3 to $70 \mathrm{kDa}$ also decreased linearly with hydrodynamic radius in different mono- and polyspecies biofilms, and were up to 150 times smaller than those in bulk water. However, the direct comparison of their results with our study is difficult because the microbial cell distribution is rather different in a biofilm and in a food matrix such as cheese. To our knowledge, only two studies are realistically comparable to our system (Rani et al., 2005 and Takenaka et al., 2009). They focused the analysis of the solute diffusion exclusively within identified clusters of microbial cells inside different model oral biofilms. The diffusive penetration of two tracer molecules (rhodamine B and fluorescein, $\mathrm{MW} \sim 400 \mathrm{Da}$, chosen as model of antibiotic for their similar size), into staphylococcal cell clusters was directly visualized by confocal 
scanning laser microscopy (Rani et al., 2005). The effective diffusion coefficients of the two fluorescent tracers were around 10 times lower than the corresponding solute diffusion coefficient in water. The difference with the present study could be due to a denser population of cells in our colonies. The diffusive penetration of fluorescently-labeled dextrans of various molecular weights (from 3 to $70 \mathrm{kDa}$ ) was visualized into three different species of cell clusters formed by oral bacteria grown in a flow cell (Takenaka et al., 2009). Like in the present study, the effective diffusion coefficient of dextrans strongly decreased with their molecular weights. However, their order of magnitude was different from our results, with effective diffusion coefficients only twice smaller than those in water. For Thurnheer et al. (2003), analysis of diffusion phenomena within biofilms suggested tortuosity as the most probable factor responsible for retarded diffusion compared to water. They defined a tortuosity index, as the square root of $D_{\mathrm{w}} / D_{\text {in }}$, representing an indicator of solute diffusion through interstitial space between bacterial cells. A molecule going through a highly convoluted threedimensional route in a matrix will be delayed in comparison with free diffusion in water. As shown in Table 3, the tortuosity indexes estimated from our experimental data were of the same order of magnitude regardless of the L. lactis strain and the size of the diffusing dextran solutes. In our conditions, the extracellular space between the lactococci cells within the colony is filled with an aqueous phase composed of water, lactose, and minerals (Floury et al., 2013), thus explaining why the tortuosity index did not depend on the size of the dextrans.

In conclusion about the diffusion of dextrans within bacterial colony, we confirmed that macromolecules as large as dextrans of $155 \mathrm{kDa}$ diffused into lactococci colonies in a model cheese (Floury et al., 2013). We demonstrated that their diffusion was similar for two different strains of lactoccoci whatever the size of dextrans up to $155 \mathrm{kDa}$.

\section{Milk Proteins, Such as BSA, Lactoferrin and $\alpha_{S 1}$-Casein, Do Not Diffuse Inside neither LD61 nor TIL1230 Lactococci Colonies}

The typical fluorescence intensity profiles for three fluorescentlylabeled proteins, and typical images of the corresponding colonies at the end of the experiments are shown on Figures 7-9. Whereas, the fluorescence intensity of the three proteins outside the colonies increased with time, the fluorescence intensity measured inside the colonies was very low all along the duration of the experiments. The increase of the fluorescence intensity throughout time outside the colonies shows that the three

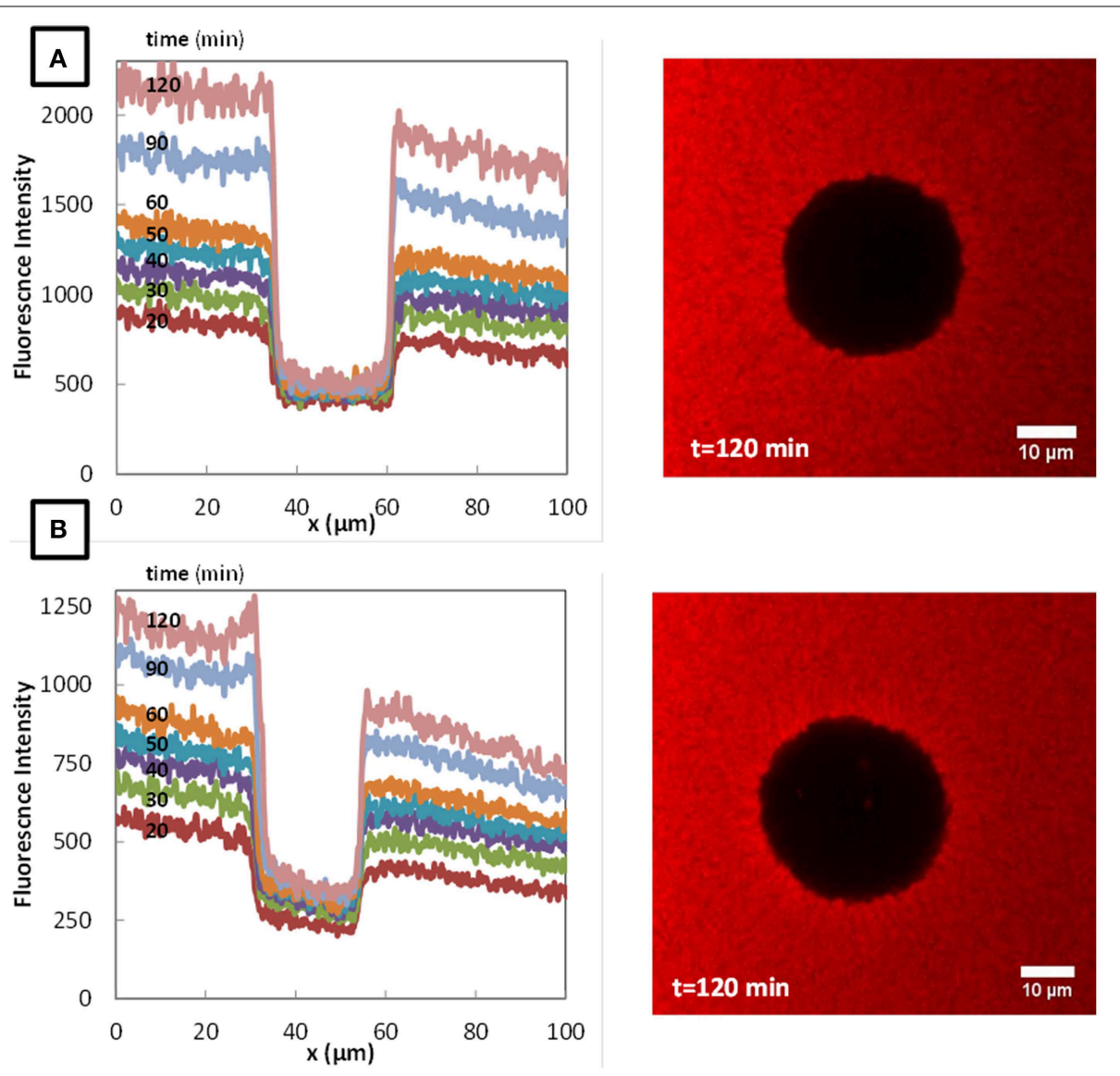

FIGURE 7 | Fluorescence profiles of fluorescently-labeled Bovine Serum Albumin (BSA), in colonies of Lactococcus lactis LD61 (A) and TIL 1230 (B) at different times from 20 to $120 \mathrm{~min}$ after the deposit at the surface of a model cheese and the corresponding microscopic observations of the colony after $120 \mathrm{~min}$ of diffusion. 

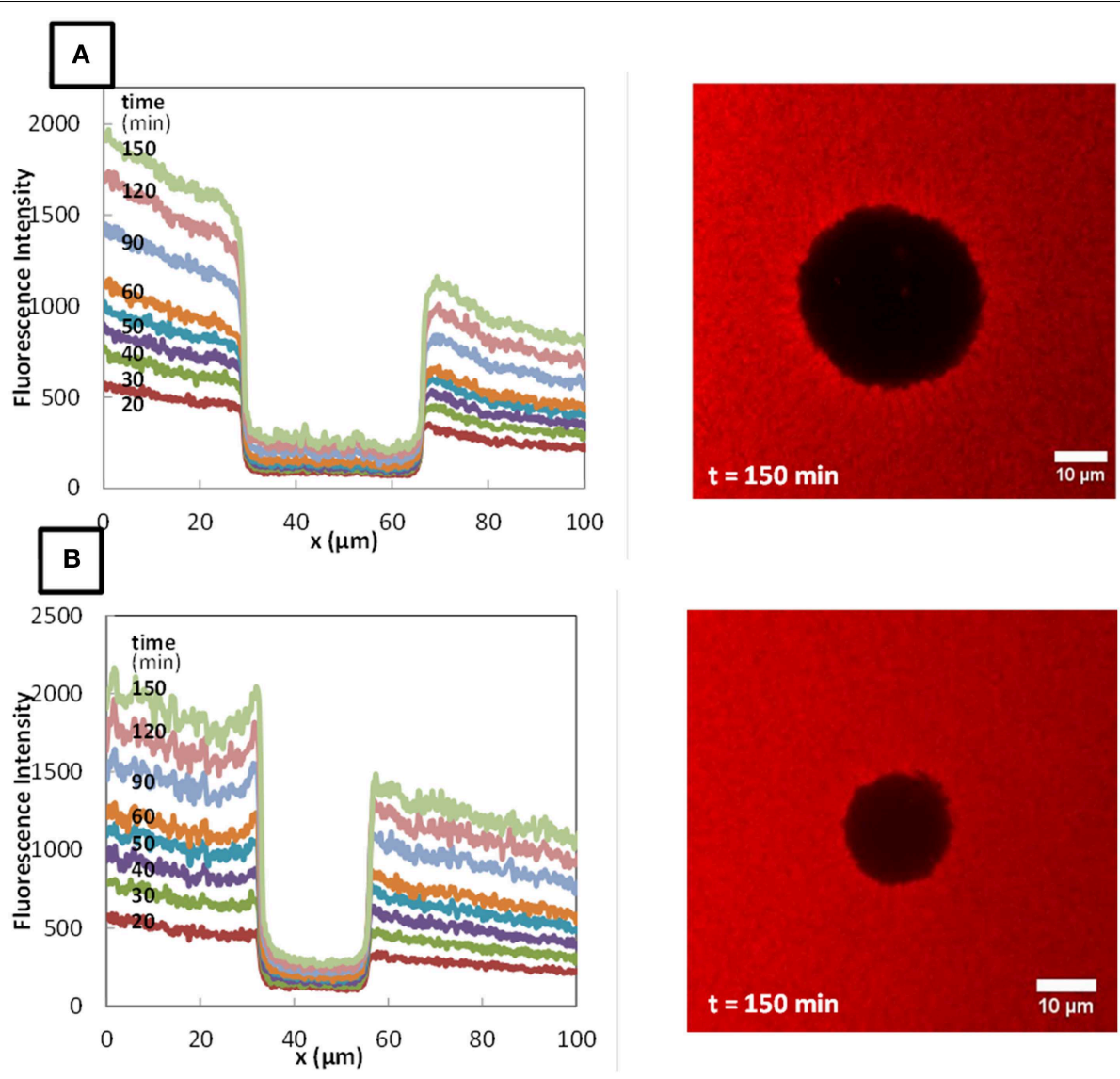

FIGURE 8 | Fluorescence profiles of RITC-LF in Lactococcus lactis LD61 (A) and TIL1230 (B) from 20 to 150 min and corresponding microscopic observations of the colony after $150 \mathrm{~min}$ of diffusion.

labeled-proteins effectively diffused in the surrounding cheese matrix. Whereas, the fluorescence outside the colonies was finally intense, the observation of the micrographs clearly confirmed the intensity profiles by the absence of fluorescence inside the colonies. This means that, surprisingly, none of the three proteins could diffuse inside the bacterial colonies, although their hydrodynamic radii were much smaller than the radius of the largest dextran (Table 1). Concerning the diffusion of proteins in cell clusters, to our knowledge the only published study is from Takenaka et al. (2009).Contrary to our results, they clearly visualized by time-lapse confocal microscopic observations that fluorescently-labeled proteins, even the largest like ConA (MW $104 \mathrm{kDa}$ ) and IgG (MW $150 \mathrm{kDa}$ ), diffused inside microbial cell clusters that were approximately a few hundred micrometers in diameter and reached the center of these cell clusters in less than $3 \mathrm{~min}$.

These results highlighted that the size of the diffusing solute was not the sole factor conditioning its ability to enter inside colonies of $L$. lactis immobilized in cheese. Other physicochemical factors such as flexibility, charge and/or hydrophobicity of the solute can also be of involved, by generating bacteria-solute interactions of different nature, especially for diffusing solutes such as milk proteins. Moreover, the impact of these factors can also depend on the surface properties of the strain (Habimana et al., 2011).
When diffusing through a non-inoculated model cheese, the rigid, and globally negatively charged BSA protein was hindered more than dextrans with a similar hydrodynamic radius, because of the existence of solute-matrix interactions (Silva et al., 2013). In the same way, deBeer et al. (1997) and Takenaka et al. (2009) reported that diffusion coefficients of solutes in different kinds of cell clusters were conditioned on the network structure in the interstitial space, but also mainly depended on the size and the charge of the diffusing solute. Unlike dextrans that are flexible, neutral, and hydrophilic polymers, proteins possess different shapes, hydrophobicity, and charges (Table 1). Moreover, even if the surface of the cells of the two L. lactis strains were shown to be both hydrophilic, L. lactis TIL1230 was more electronegative than LD61 at the $\mathrm{pH}$ of the model cheeses. Therefore, we could have expected the surface properties of bacterial cells to influence the ability of solutes to diffuse or not inside the colony by generating either repulsive or attractive interactions like electrostatic forces, depending on the charge of the solute (Burgain et al., 2014). The $\mathrm{pH}$ of the model cheeses were around 5.1 and 5.3 for LD61 and TIL1230, respectively. Therefore, according to the isoelectric point of the proteins (Table 1), the net charges of BSA and $\alpha$-s1 casein were slightly negative, whereas LF was globally positively charged in both cheese matrices. Electrostatic repulsions could have then occurred between the outer bacterial cells of the colony and the negatively charged solutes, preventing their diffusion 


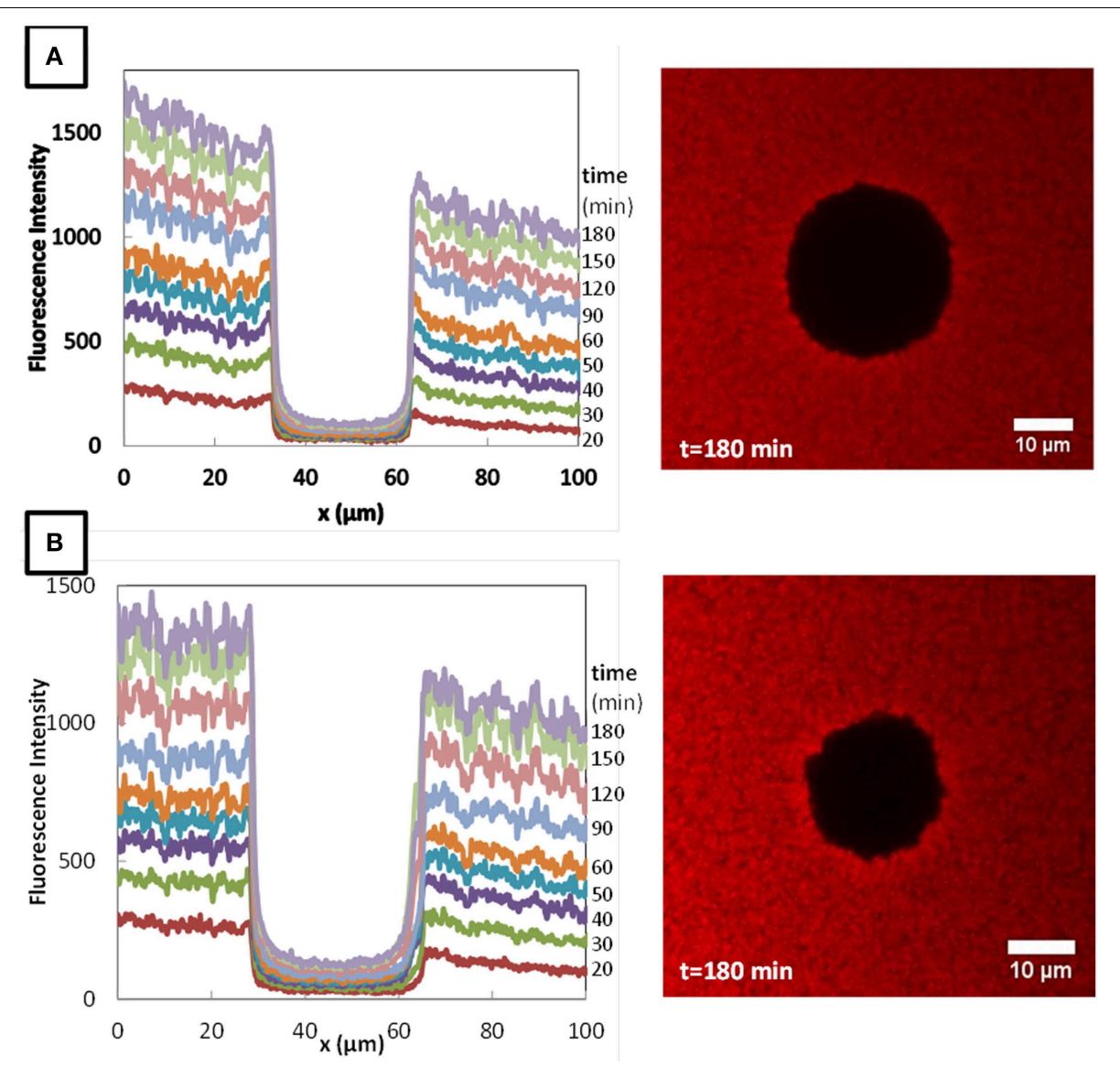

FIGURE 9 | Fluorescence profiles of RITC- $\alpha_{\mathrm{S} 1}$-casein in Lactococcus lactis LD61 (A) and TIL1230 (B) from 20 to 180 min and corresponding microscopic observations of the colony after $180 \mathrm{~min}$ of diffusion.

inside colony. However, it is largely known that cheese is a medium presenting a high ionic strength (around $100 \mathrm{mM}$ ). In that case, the Debye length is very small (around $2 \mathrm{~nm}$ ) and then the energy barrier due to repulsive forces is very low, meaning that the electrostatic contribution is strongly suppressed (Burgain et al., 2011). Interactions of electrostatic nature were not explaining the non-ability of the three milk proteins to penetrate inside L. lactis colonies immobilized in cheese. Other kind of repulsive forces such as hydrophobic interactions can be involved, especially between the hydrophobic BSA and LF proteins and the hydrophilic surfaces of the cells of both L. lactis strains. However, for the amphiphilic $\alpha$-s1 casein, there was no reason for repulsions of hydrophobic origin with the bacterial surfaces.

We were finally not able to explain why $\alpha$-s1 casein proteins could not diffuse inside the lactococci colonies. However, it is well-known that milk caseins, especially the $\alpha$-s1 casein, are hydrolyzed by the cell wall proteases of $L$. lactis in cheese and/or other proteases present in the cheese. We can thus hypothesize that some of the generated peptides can diffuse inside colonies, and are further metabolized into smaller peptides and amino acids by all the cells located inside the colonies, as strongly suggested by the results obtained in the same model cheese by Le Boucher et al. (personal communication).

\section{Conclusion}

Effective diffusion coefficients of dextran macromolecules were quantified for the first time inside colonies of two different $L$. lactis strains immobilized in a model cheese. We clearly showed that the diffusion behavior of macromolecules through bacterial colonies immobilized in a model cheese not only depends on the size of the diffusing solutes, but also and mainly on their physicochemical properties. Whereas, a flexible and neutral hydrophilic polymer such as a dextran can diffuse inside colonies whatever its size, none of the three proteins investigated in this study could penetrate inside lactococci colonies. These original results remain unexplained because both the surface of the two bacterial strains and the three diffusing proteins presented various physicochemical properties, from rigid to flexible shapes, and from negatively to neutral and positively charged. Our results finally show that the choice of the fluorescently-labeled molecule as a model of diffusing solute is crucial.

\section{Acknowledgments}

This study was part of the CheeseOmic Project co-funded by the regions Bretagne and Pays-de-la-Loire and supported by Bretagne Biotechnologie Alimentaire (BBA) association. 


\section{References}

Aly, S., Floury, J., Famelart, M. H., Madec, M. N., Dupont, D., Le Gouar, Y., et al. (2011). Nisin quantification by ELISA allows the modeling of its apparent diffusion coefficient in model cheeses. J. Agric. Food Chem. 59, 9484-9490. doi: 10.1021/jf2008474

Böhme, U., and Scheler, U. (2007). Effective charge of bovine serum albumin determined by electrophoresis NMR. Chem. Phys. Lett. 435, 342-345. doi: 10.1016/j.cplett.2006.12.068

Bokkhim, H., Bansal, N., GrØndahl, L., and Bhandari, B. (2013). Physico-chemical properties of different forms of bovine lactoferrin. Food Chem. 141, 3007-3013. doi: 10.1016/j.foodchem.2013.05.139

Boonaert, C. J., and Rouxhet, P. G. (2000). Surface of lactic acid bacteria: relationships between chemical composition and physicochemical properties. Appl. Environ. Microbiol. 66, 2548-2554. doi: 10.1128/AEM.66.6.25482554.2000

Boulos, L., Prévost, M., Barbeau, B., Coallier, J., and Desjardins, R. (1999). LIVE/DEAD ${ }^{\circledR}$ BacLight $^{\mathrm{TM}}$ : application of a new rapid staining method for direct enumeration of viable and total bacteria in drinking water. J. Microbiol. Methods 37, 77-86. doi: 10.1016/S0167-7012(99)00048-2

Briandet, R., Lacroix-Gueu, P., Renault, M., Lecart, S., Meylheuc, T., Bidnenko, E., et al. (2008). Fluorescence correlation spectroscopy to study diffusion and reaction of bacteriophages inside biofilms. Appl. Environ. Microbiol. 74, 2135-2143. doi: 10.1128/AEM.02304-07

Brocklehurst, T. (1995). The effect of transient temperatures on the growth of Salmonella typhimurium LT2 in gelatin gel. Int. J. Food Microbiol. 27, 45-60. doi: 10.1016/0168-1605(94)00152-V

Burgain, J., Gaiani, C., Linder, M., and Scher, J. (2011). Encapsulation of probiotic living cells: from laboratory scale to industrial applications. J. Food Eng. 104, 467-483. doi: 10.1016/j.jfoodeng.2010.12.031

Burgain, J., Scher, J., Lebeer, S., Vanderleyden, J., Cailliez-Grimal, C., Corgneau, M., et al. (2014). Significance of bacterial surface molecules interactions with milk proteins to enhance microencapsulation of Lactobacillus rhamnosus GG. Food Hydrocoll. 41, 60-70. doi: 10.1016/j.foodhyd.2014.03.029

Chaufer, B., Rabiller-Baudry, M., Lucas, D., Michel, F., and Timmer, M. (2000). Selective extraction of lysozyme from a mixture with lactoferrin by ultrafiltration. Role of the physico-chemical environment. Le Lait 80, 197-203. doi: 10.1051/lait:2000119

Crank, J. (1975). The Mathematics of Diffusion, 2nd Edn. Oxford: Clarendon Press.

deBeer, D., Stoodley, P., and Lewandowski, Z. (1997). Measurement of local diffusion coefficients in biofilms by microinjection and confocal microscopy. Biotechnol. Bioeng. 53, 151-158.

Floury, J., Jeanson, S., Aly, S., and Lortal, S. (2010). Determination of the diffusion coefficients of small solutes in cheese: a review. Dairy Sci. Technol. 90, 477-508. doi: $10.1051 / \mathrm{dst} / 2010011$

Floury, J., Jeanson, S., Madec, M.-N., and Lortal, S. (2013). Porosity of Lactococcus lactis subsp. lactis LD61 colonies immobilised in model cheese. Int. J. Food Microbiol. 163, 64-70. doi: 10.1016/j.ijfoodmicro.2013.02.014

Floury, J. M. N., Madec, F., Waharte, S., Jeanson, S., and, S., Lortal (2012). First assessment of diffusion coefficients in model cheese by fluorescence recovery after photobleaching (FRAP). Food Chem. 133, 551-556. doi: 10.1016/j.foodchem.2012.01.030

Giaouris, E., Chapot-Chartier, M.-P., and Briandet, R. (2009). Surface physicochemical analysis of natural Lactococcus lactis strains reveals the existence of hydrophobic and low charged strains with altered adhesive properties. Int. J. Food Microbiol. 131, 2-9. doi: 10.1016/j.ijfoodmicro.2008.09.006

Guiot, E., Georges, P., Brun, A., Fontaine-Aupart, M. P., Bellon-Fontaine, M. N., and Briandet, R. (2002). Heterogeneity of diffusion inside microbial biofilms determined by fluorescence correlation spectroscopy under two-photon excitation. Photochem. Photobiol. 75, 570-578. doi: 10.1562/0031-8655(2002)075<0570:HODIMB > 2.0.CO;2

Habimana, O., Le Goff, C., Juillard, V., Bellon-Fontaine, M.-N., Buist, G., Kulakauskas, S., et al. (2007). Positive role of cell wall anchored proteinase PrtP in adhesion of lactococci. BMC Microbiol. 7:36. doi: 10.1186/1471-2180-7-36

Habimana, O., Steenkeste, K., Fontaine-Aupart, M.-P., Bellon-Fontaine, M.-N., Kulakauskas, S., and Briandet, R. (2011). Diffusion of nanoparticles in biofilms is altered by bacterial cell wall hydrophobicity. Appl. Environ. Microbiol. 77, 367-368. doi: 10.1128/AEM.02163-10

Jeanson, S., Chad uf, J., Madec, M. N., Aly, S., Floury, J., Brocklehurst, T. F., et al. (2011). Spatial distribution of bacterial colonies in a model cheese. Appl. Environ. Microbiol. 77, 1493-1500. doi: 10.1128/AEM.02233-10

Kreft, J. U., Booth, G., and Wimpenny, J. W. (1998). BacSim, a simulator for individual-based modelling of bacterial colony growth. Microbiol. Read. Engl. 144(Pt. 12), 3275-3287. doi: 10.1099/00221287-144-12-3275

Lacroix-Gueu, P., Briandet, R., Leveque-Fort, S., Bellon-Fontaine, M. N., and Fontaine-Aupart, M. P. (2005). In situ measurements of viral particles diffusion inside mucoid biofilms. C. R. Biol. 328, 1065-1072. doi: 10.1016/j.crvi.2005.09.010

Ly, M. H., Naïtali-Bouchez, M., Meylheuc, T., Bellon-Fontaine, M.-N., Le, T. M., Belin, J.-M., et al. (2006). Importance of bacterial surface properties to control the stability of emulsions. Int. J. Food Microbiol. 112, 26-34. doi: 10.1016/j.ijfoodmicro.2006.05.022

Marchin, S., Putaux, J.-L., Pignon, F., and Léonil, J. (2007). Effects of the environmental factors on the casein micelle structure studied by cryo transmission electron microscopy and small-angle $\mathrm{x}$-ray scattering/ultrasmallangle X-ray scattering. J. Chem. Phys. 126, 045101. doi: 10.1063/1.2409933

McKay, A. L., Peters, A. C., and Wimpenny, J. W. T. (1997). Determining specific growth rates in different regions of Salmonella typhimurium colonies. Lett. Appl. Microbiol. 24, 74-76. doi: 10.1046/j.1472-765X.1997.00354.x

Rani, S. A., Pitts, B., and Stewart, P. S. (2005). Rapid diffusion of fluorescent tracers into Staphylococcus epidermidis biofilms visualized by time lapse microscopy. Antimicrob. Agents Chemother. 49, 728-732. doi: 10.1128/AAC.49.2.728732.2005

Silva, J. V. C., Peixoto, P. D. S., Lortal, S., and Floury, J. (2013). Transport phenomena in a model cheese: the influence of the charge and shape of solutes on diffusion. J. Dairy Sci. 96, 6186-6198. doi: 10.3168/jds.2013-6552

Takenaka, S., Pitts, B., Trivedi, H. M., and Stewart, P. S. (2009). Diffusion of macromolecules in model oral biofilms. Appl. Environ. Microbiol. 75, 1750-1753. doi: 10.1128/AEM.02279-08

Thurnheer, T., Gmur, R., Shapiro, S., and Guggenheim, B. (2003). Mass transport of macromolecules within an in vitro model of supragingival plaque. Appl. Environ. Microbiol. 69, 1702-1709. doi: 10.1128/AEM.69.3.17021709.2003

Wimpenny, J. W. T. (1992). "Microbial systems," in Advances in Microbial Ecology, ed K. C. Marshall (Boston, MA: Springer US), 469-522. Available online at: http://link.springer.com/10.1007/978-1-4684-7609-5_10 (Accessed February 2, 2015).

Conflict of Interest Statement: The authors declare that the research was conducted in the absence of any commercial or financial relationships that could be construed as a potential conflict of interest.

Copyright (C) 2015 Floury, El Mourdi, Silva, Lortal, Thierry and Jeanson. This is an open-access article distributed under the terms of the Creative Commons Attribution License (CC BY). The use, distribution or reproduction in other forums is permitted, provided the original author(s) or licensor are credited and that the original publication in this journal is cited, in accordance with accepted academic practice. No use, distribution or reproduction is permitted which does not comply with these terms. 